\title{
Performance Improvement of Microstrip Patch Antenna using Substrate with Lower Relative Permittivity
}

\author{
Vikrant Thakur \\ M. Tech. Scholar \\ DIT, Dehradun
}

\author{
Dhruva Chaudhary \\ Asst. Professor \\ DIT, Dehradun
}

\begin{abstract}
Antenna with higher directivity and compact size is the need of hour, latest trends suggest that lot of work has been going on in this field. In this paper the performance of patch antenna with substrate having higher relative permittivity has been compared with that of patch antenna with substrate having low value of relative permittivity. The simulation results suggests that patch antenna with lower relative permittivity substrate has better value of directivity and return loss, these parameters play significant role in antenna designing.
\end{abstract}

\section{Keywords}

Patch antenna, Directivity, Return Loss.

\section{INTRODUCTION}

According to IEEE standard an antenna is a part of a transmitting or receiving system that is designed to radiate or to receive electromagnetic waves. [1].As compared to conventional antenna microstrip patch antennas are low profiles, low cost to production and compatible with microwave monolithic integrated circuit and optoelectronic integrated circuit technology. That is the reason these antenna find application in mobile communications, satellite communication and missile system. These antennas are very versatile in terms of resonant frequency, polarization, pattern and impedance. [2]

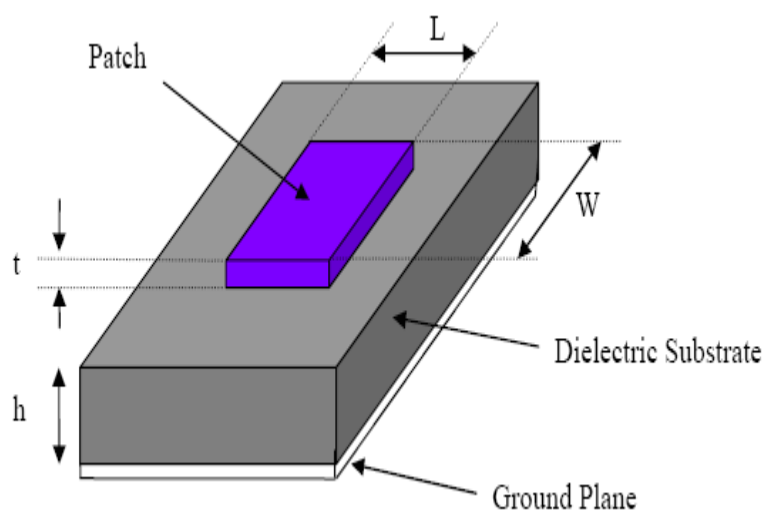

Fig.1 Microstrip Patch Antenna

These antennas are designed on a dielectric substrate which is composed of a radiating patch on one side and ground plane on another side as shown in Fig.1. In spite of having a lot of advantages these antennas have some drawbacks like narrow bandwidth, low gain etc. [3] To improve these drawbacks patch antenna various researches have been done. One of them is to use a substrate with lower value of relative permittivity. [4][5]
In this research work the simulation analysis of patch antennas having substrate of different relative permittivity has been carried out and their performance analysis is done.

\section{DESIGNING OF MICROSTRIP}

\section{PATCH ANTENNA}

While designing microstrip antenna the height of substrate, relative pemittivity of substrate and frequency are specified at first, then on the basis of these constraints other parameters like, width (w) and length (L) are determined.For simulation purpose microstrip antenna with different substrate ( substrate with different relative permittivity) has been designed.

Figure 2 shows the patch antenna having substrate with relative permittivity 4.4 . Basically the substrate material is FR4_epoxy.It has relative permeability 1.0.

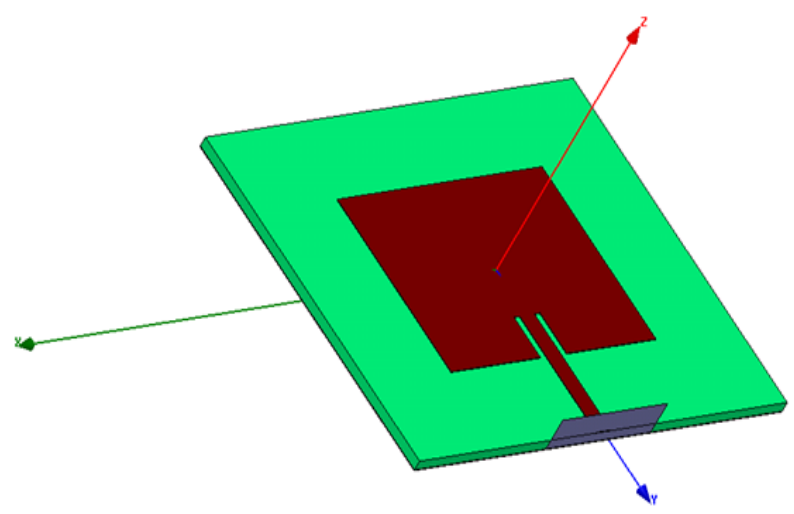

Fig.2 Patch Antenna (Substrate Relative Relative permittivity 4.4)

Table 1: Specification of first Antenna

\begin{tabular}{|l|l|l|}
\hline S.N. & Quantity & Value \\
\hline 1 & Relative permittivity of substrate & 4.4 \\
\hline 2 & Height & $1.6 \mathrm{~mm}$ \\
\hline 3 & Frequency & $2.4 \mathrm{GHz}$ \\
\hline
\end{tabular}

Other parameters of this antenna has been determined using following equations [2]

Calculation of Width W

$w=\frac{1}{2 f_{r \sqrt{\mu_{0} \varepsilon_{0}}}} \sqrt{\frac{2}{\varepsilon_{r}+1}}=\frac{C}{2 f_{r}} \sqrt{\frac{2}{\varepsilon_{r}+1}}$ 
Where $\mathrm{C}=$ velocity of light in free space $\varepsilon_{\mathrm{r}}=$ Relative permittivity of substrate

Calculating actual length of patch (L)

$$
L=L_{e f f}-2 \Delta L
$$

Where

$$
L_{e f f}=\frac{c}{2 f_{r} \sqrt{\varepsilon_{e f f}}}
$$

Calculation of $\varepsilon_{\text {eff }}$

$\varepsilon_{\text {eff }}=\frac{\varepsilon_{r}+1}{2}+\frac{\varepsilon_{r}-1}{2}\left(\frac{1}{\sqrt{1+\frac{12 h}{w}}}\right)$

Calculation of length extension

$$
\frac{\Delta L}{\mathrm{~h}}=0.412 \frac{\left.\left(\varepsilon_{e f f}+0.3\right)\left(\frac{w}{h}+0.264\right)\right)}{\left(\varepsilon_{e f f}-0.258\right)\left(\frac{w}{h}+0.8\right)}
$$

Table 2: The calculated value for different quantities

\begin{tabular}{|l|l|l|}
\hline S.N. & Quantity & Calculated Value \\
\hline 1 & Width & $38 \mathrm{~mm}$ \\
\hline 2 & Length L & $29.26 \mathrm{~mm}$ \\
\hline
\end{tabular}

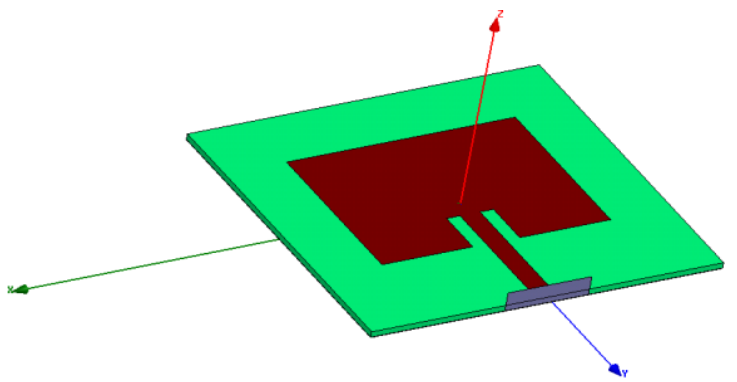

Fig. 3 Patch Antenna (Substrate Relative permittivity 2.2)

Figure 3 shows the patch antenna which has relative permittivity of substrate 2.2 . Basically the substrate material is Rogers RT/duroid 5880.It has relative permeability 1.0.

\section{Table 3: Specification of second Antenna}

\begin{tabular}{|l|l|l|}
\hline S.N. & Quantity & Specified Value \\
\hline 1 & Relative permittivity of substrate & 2.2 \\
\hline 2 & Height & $1.6 \mathrm{~mm}$ \\
\hline 3 & Frequency & $2.4 \mathrm{GHz}$ \\
\hline
\end{tabular}

The calculated values for different quantities by equations (1),

(2), (3), (4) and (5) are as shown in table 4.

Table 4: Calculated quantities of second Antenna

\begin{tabular}{|l|l|l|}
\hline S.N. & Quantity & Calculated Value \\
\hline 1 & Width & $49.4 \mathrm{~mm}$ \\
\hline 2 & Length L & $42.51 \mathrm{~mm}$ \\
\hline
\end{tabular}

\section{RESULTS AND ANALYSIS}

Both the antenna models with different parameters have been simulated. We get the following results-

(i) Figure 4(a) shows the return loss for antenna with substrate $\left(\varepsilon_{\mathrm{r}}=4.4\right)$. It has return loss $-13.19 \mathrm{~dB}$. Figure 4(b) return loss of second antenna with substrate $\left(\varepsilon_{\mathrm{r}}=2.2\right)$.It has improved value $28.51 \mathrm{~dB}$

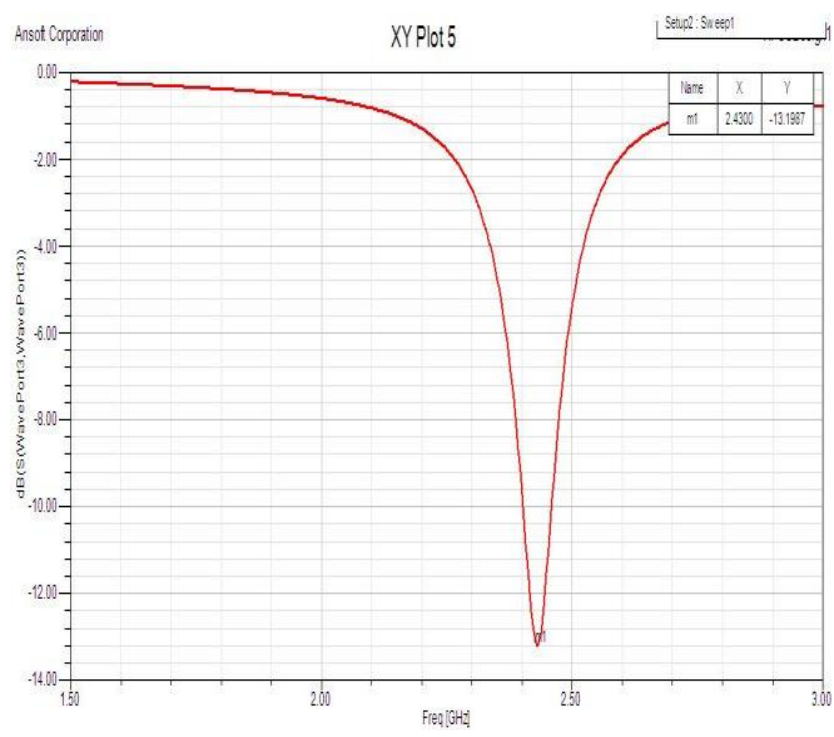

Fig. 4 (a) Return loss for first antenna

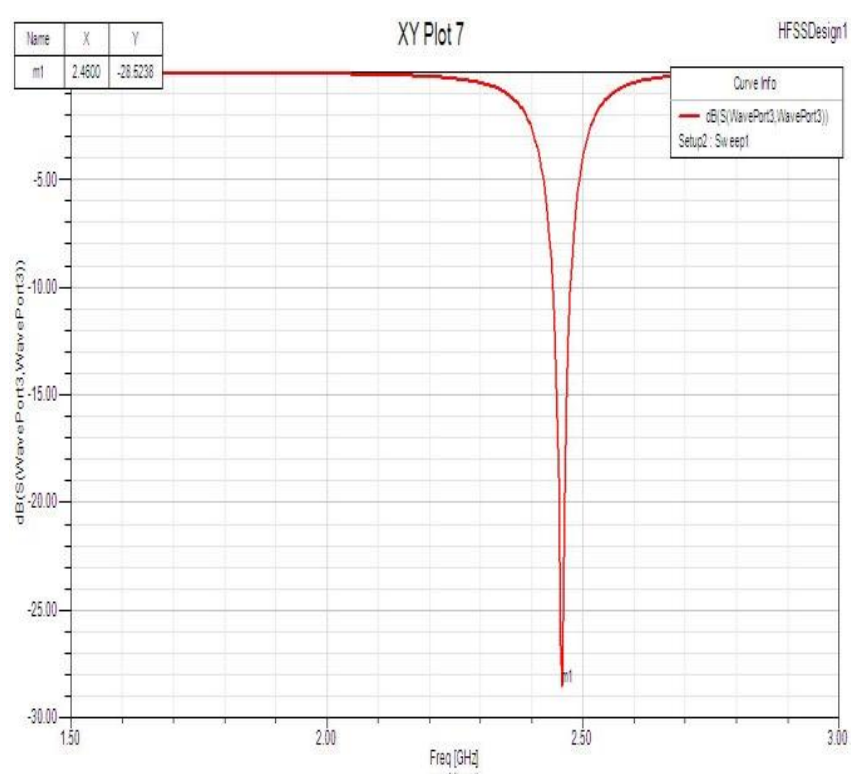

Figure 4(b) Return loss for second antenna

(ii) Figure 5(a) shows the directivity of patch antenna with substrate $\left(\varepsilon_{\mathrm{r}}=4.4\right)$.It has the value $4.74 \mathrm{dBi}$. Figure $5(\mathrm{~b})$ shows directivity of second antenna with substrate $\left(\varepsilon_{\mathrm{r}}=2.2\right)$.It has improved value $6.93 \mathrm{dBi}$. 


\begin{tabular}{|c|c|c|c|}
\hline Name & Theta & Ang & Mag \\
\hline $\mathrm{m} 1$ & 360.0000 & -0.0000 & 4.7451 \\
\hline
\end{tabular}

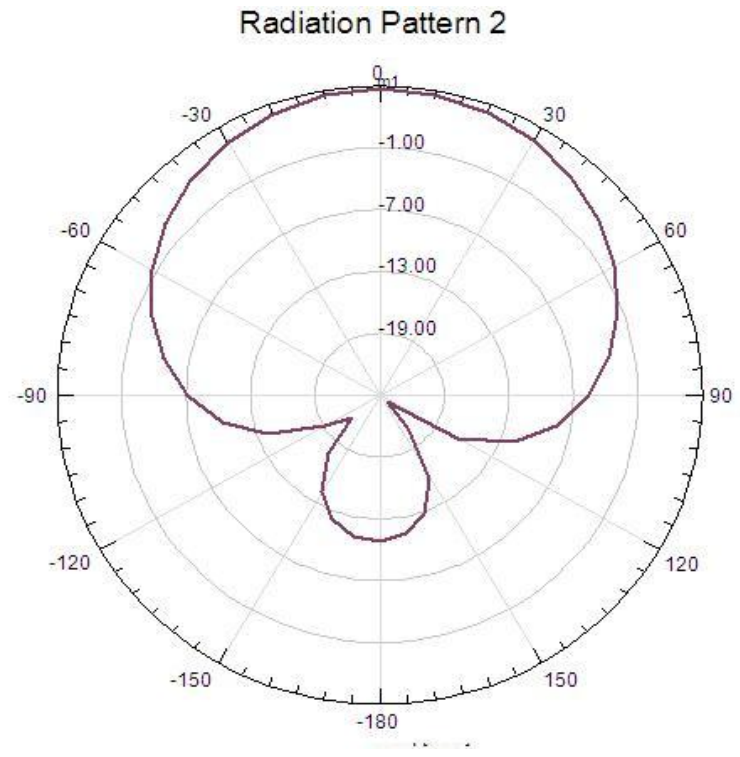

HFSSDesign 1

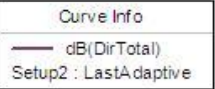

Fig. 5(a) Radiation Pattern showing directivity of magnitude 4.74 for first antenna
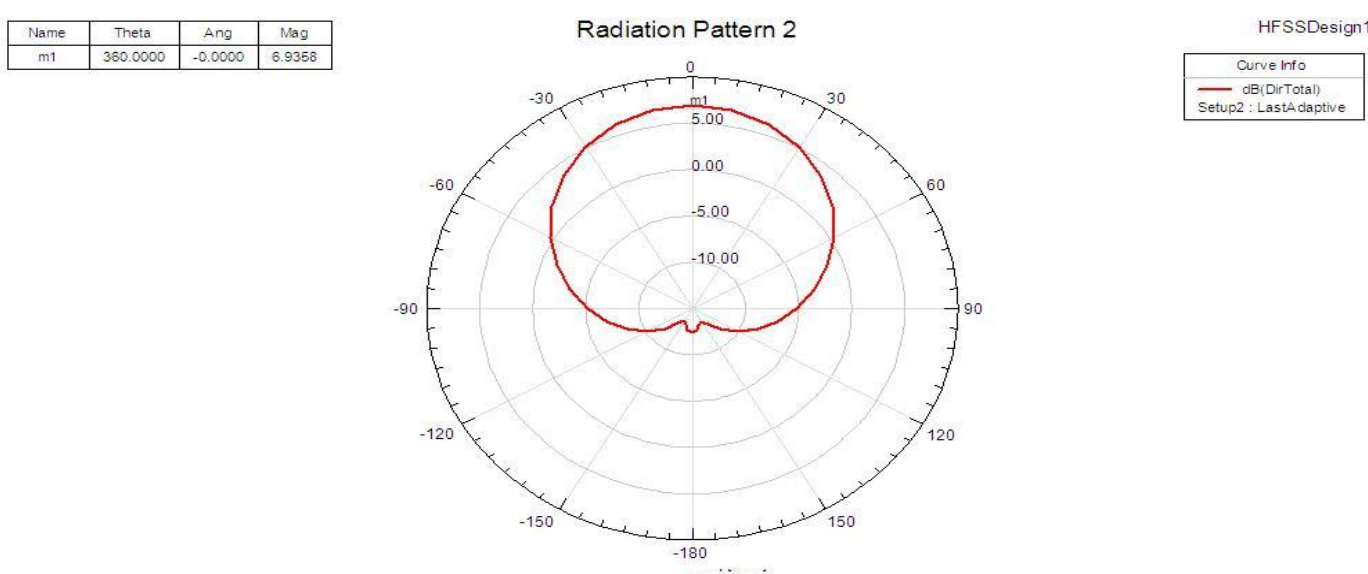

Figure 5(b) Radiation Pattern showing directivity of magnitude 6.93 for second antenna

\section{CONCLUSION}

The simulation result shows that the patch antenna with lower value of substrate relativity has improved value of return loss and directivity. The return loss has changed from $-13.19 \mathrm{~dB}$ to $-28.51 \mathrm{~dB}$ from first antenna to second antenna. Directivity has improved from $4.74 \mathrm{dBi}$ to $6.93 \mathrm{dBi}$ for first antenna to second antenna.

\section{REFERENCES}

[1] "IEEE standard definitions of terms for antennas," IEEE Std 145-1983, 1983.

[2] "Balanis CA Antenna Theory ;Analysis and Design John Wiley and Sons Inc.

[3] Gupta V, Dhaliwal BS (2011). Performance Enhancement of Recangular Microstrip Patch Antenna by Loading Complementary Split Ring Resonator in the Patch, Inter. J. of Elec. Engg. 3 (1):141-143.

[4] Z. Awang, Microwave Engineering for Wireless Communications: Prentice Hall, 2006
[5] D. M. Pozar, Microwave Engineering: Wiley Interscience, 2006.

[6] Bimal Garg et al " Analysis and design of microstrip patch antenna loaded with innovative metamaterial structure Research Journal of Physical and Applied Science Vol. 1(1), pp. 013 - 019, August 2012

[7] Stutzman WL, Thiele GA (1998).Antenna Theory and Design. John Wiley and Sons, 2nd Ed.

[8] Z. Awang, Microwave Engineering for Wireless Communications: Prentice Hall, 2006

[9] D. M. Pozar, Microwave Engineering: Wiley Interscience, 2006.

[10] Bimal Garg et al " Analysis and design of microstrip patch antenna loaded with innovative metamaterial structure Research Journal of Physical and Applied Science Vol. 1(1), pp. 013 - 019, August 2012

[11] Stutzman WL, Thiele GA (1998).Antenna Theory and Design. John Wiley and Sons, 2nd Ed. 